\title{
Interleukin-10 deficiency exacerbates inflammation-induced tau pathology
}

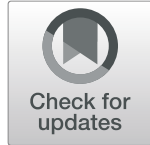

Lea L. Weston', Shanya Jiang ${ }^{1}$, Devon Chisholm¹, Lauren L. Jantzie ${ }^{2}$ and Kiran Bhaskar ${ }^{1,3^{*}}$

\begin{abstract}
Background: The presence of hyperphosphorylated microtubule-associated protein tau is strongly correlated with cognitive decline and neuroinflammation in Alzheimer's disease and related tauopathies. However, the role of inflammation and anti-inflammatory interventions in tauopathies is unclear. Our goal was to determine if removing antiinflammatory interleukin-10 (IL-10) during an acute inflammatory challenge has any effect on neuronal tau pathology.

Methods: We induce systemic inflammation in $/ 110$-deficient $\left(\| 10^{-/-}\right.$) versus $/ 110^{+/+}$(Non-Tg) control mice using a single intraperitoneal (i.p.) injection of lipopolysaccharide (LPS) to examine microglial activation and abnormal hyperphosphorylation of endogenous mouse tau protein. Tau phosphorylation was quantified by Western blotting and immunohistochemistry. Microglial morphology was quantified by skeleton analysis. Cytokine expression was determined by multiplex electro chemiluminescent immunoassay (MECl) from Meso Scale Discovery (MSD).

Results: Our findings show that genetic deletion of I/10 promotes enhanced neuroinflammation and tau phosphorylation. First, LPS-induced tau hyperphosphorylation was significantly increased in $1 / 10^{-/-}$mice compared to controls. Second, LPStreated $\| 10^{-1-}$ mice showed signs of neurodegeneration. Third, LPS-treated $\| 10^{-1-}$ mice showed robust IL-6 upregulation and direct treatment of primary neurons with IL-6 resulted in tau hyperphosphorylation on Ser396/Ser404 site.

Conclusions: These data support that loss of IL-10 activates microglia, enhances IL-6, and leads to hyperphosphorylation of tau on AD-relevant epitopes in response to acute systemic inflammation.
\end{abstract}

Keywords: Alzheimer's disease, Tau, Microglia, Neuroinflammation, Interleukin-10

\section{Background}

Alzheimer's disease (AD) is one of the tauopathies and the most common neurodegenerative disease involving the abnormal phosphorylation and accumulation of the microtubule-associated protein tau (MAPT or tau). Tau is a neuron-enriched protein known to bind and stabilize microtubules under homeostatic conditions and has non-microtubule-binding functions $[1,2]$. However, in tauopathies, tau acquires abnormal toxic forms via

\footnotetext{
* Correspondence: KBhaskar@salud.unm.edu

${ }^{1}$ Department of Molecular Genetics and Microbiology, University of New Mexico, MSC08 4660, 1 University of New Mexico, Albuquerque, NM 87131, USA

${ }^{3}$ Department of Neurology, University of New Mexico, 1 University of New Mexico, Albuquerque, NM 87131, USA

Full list of author information is available at the end of the article
}

various post-translational modifications that lead to loss of tau's function or gain of toxic function [2-4]. The presence of hyperphosphorylated tau has been shown to strongly correlate with cognitive decline [5-7] and neuroinflammation $[8,9]$. Increasing evidence suggests neuroinflammation is a major component of tauopathies including $\mathrm{AD}[10,11]$. Additionally, previous studies suggest that activated (pro-inflammatory) microglia are sufficient to induce hyperphosphorylation of tau both in vivo and in vitro [12]. Furthermore, in vivo animal models suggest that inflammation precedes and contributes to tau pathology [12]. Therefore, understanding the role of anti-inflammatory molecules is important in thwarting excessive neuroinflammation that contributes to tau pathology relevant to AD and related tauopathies. 
Interleukin-10 (IL-10) is a well-establishedantiinflammatory cytokine with an important role in preventing unrestrained inflammatory responses from activated immune cells $[13,14]$. The central nervous system (CNS) resident cells, microglia and astrocytes, are both major producers of IL-10, in vitro [15]. However, a recent single cell transcriptome analysis of IL-10 production in microglia raises questions about whether microglia produce IL-10 after endotoxin challenge, in vivo [16]. IL-10 plays a role in downregulating inflammatory responses in a variety of cell types [17] including microglia in the brain [18]. Furthermore, a known single nucleotide polymorphism in the promoter region of $\mathrm{Il} 10$ is associated with abnormal hippocampus-dependent memory function [19] and increased risk for AD in human subjects [20-22]. Therefore, the potential of IL-10 in reducing brain inflammation and subsequent tau pathology is understudied and important to determine in the context of AD. Interestingly, a compelling study by Chackrabarty et al. has suggested that adenoassociated viral vector-mediated overexpression of IL-10 in amyloid-precursor protein (APP) mouse model of AD exacerbated amyloid pathology and cognitive impairment due to stunted phagocytic ability of microglia [23, 24]. However, it is still unclear whether or not IL-10 plays any regulatory role in tau pathology. Based on this, we hypothesized that IL-10 plays a role in regulating the proinflammatorypathway that contributes to tau phosphorylation within the brain.

In the current study, we sought to determine if IL-10 suppresses inflammation leading to tau pathology in a model of acute systemic inflammation induced by lipopolysaccharide (LPS). We have shown that LPS-induced microglial activation promotes hyperphosphorylation of tau in non-transgenic mice through toll-like receptor 4 (TLR4) signaling. In our previous study, $1 \mathrm{mg} / \mathrm{kg}$ b.w. of LPS did not induce significant increases in AT8 or AT180 tau phosphorylation compared to vehicle-treated controls, and even $10 \mathrm{mg} / \mathrm{kg}$ b.w. of LPS had only a moderate increase in pTau in the wild-type mice [25]. This suggests a homeostatic control mechanism potentially regulated by an anti-inflammatory cytokine, such as IL-10, may exist. However, mice lacking microglial fractalkine receptor (CX3CR1) showed robust microglial activation and increased tau phosphorylation after systemic LPS treatment, supporting the importance of microglial involvement in driving tau pathology. Notably, the microglia-induced neuroinflammation and tau pathology was mediated via interleukin-1 $\beta$, (IL-1 $\beta$ ) and activation of p38 mitogen-activated protein kinase (p38 MAPK) pathway [12]. Here, to determine the contributions from IL-10 in regulated microglia-mediated tau pathology, we compared inflammatory responses in the brains of Il10deficient $\left(\mathrm{Il}_{1 \mathrm{O}^{-/-}}\right)$versus $\mathrm{Il}_{1 \mathrm{O}^{+/+}}$(Non-Tg) control mice using a moderate dose of LPS to induce systemic inflammation. We examined microglial activation and phosphorylation of tau in the hippocampi after $24 \mathrm{~h}$ of LPS treatment. We predicted that lack of IL-10 would exacerbate an ongoing inflammatory response to promote hyperphosphorylation of tau.

\section{Methods}

Animals

B6.129P2-Il10 ${ }^{\operatorname{tm} 1 C g n} / \mathrm{J}\left(I l 10^{-/-}\right)$[26] and C57BL/6J mice (Non-Tg) were both in the C57BL/6J genetic background obtained from the Jackson Laboratory (JAX stock \#002251 and \#000664). All experimental protocols involving animals were performed in accordance with the US National Institutes of Health guidelines on animal care and were approved (16-200428-BHSC; 15200352-HSC) by the Institutional Animal Care and Use Committees of the University of New Mexico.

\section{Lipopolysaccharide administration}

Vehicle (Veh, Hank's balanced saline solution, HBSS) or lipopolysaccharide (LPS, Sigma \#L2880) from Escherichia coli 055:B5 was administered ( $3 \mathrm{mg} / \mathrm{kg}$ body weight, b.w.; intraperitoneally, i.p.; single dose) to 5-6-monthold non-transgenic or $1 l 10^{-/-}$mice on C57BL/6J background. After $24 \mathrm{~h}$, the mice were sacrificed, and brain tissue was collected as described below. LPS concentration is based on previous papers showing the efficacy of this dose to induce tau phosphorylation in the hippocampi of wild-type mice [27].

\section{Brain tissue collection and preparation}

Mice were anesthetized, transcardially perfused with $0.125 \mathrm{M}$ phosphate buffer (PB) and brains were removed. Left hemispheres were fixed in $4 \%$ paraformaldehyde in $\mathrm{PB}$ (4\% PFA/PB), incubated in cryoprotection solution for $24 \mathrm{~h}$, sliced into $30 \mu \mathrm{m}$ thick sagittal brain sections, and stored at $-20^{\circ} \mathrm{C}$ in cryostorage solution until use in TUNEL and immunohistochemical analysis. Right hemispheres were micro-dissected into cortex, hippocampus, and the rest of the brain, wet weights were recorded, and the tissues were snap frozen in liquid nitrogen. The cortices and hippocampi were used in biochemical protein analysis.

\section{Multiplex electrochemiluminescent immunoassay}

Cortical tissue sections were homogenized in a buffered sucrose solution containing protease and phosphatase inhibitors and processed for protein analysis as previously described [28-30]. Tissue homogenates were spun at $4200 \times g$ at $4{ }^{\circ} \mathrm{C}$ for $10 \mathrm{~min}$. Protein concentrations of cortical lysates were determined by Bradford protein assay (Biorad). A total of $200 \mu \mathrm{g}$ of protein/sample in duplicate was used to determine cytokine levels using multiplex electrochemiluminescent immunoassay (MECI). 
The V-PLEX Plus Proinflammatory Panel 1 (mouse) electrochemiluminescent immunoassay platform (MesoScale Discovery \#K15048G, MesoScale Diagnostics LLC) was used to detect multiple cytokines, including IL-10, IL12p70, IL-1 $\beta$, TNF- $\alpha$, IL-6, and the chemokine, CXCL1. Plates were read on a Quickplex SQ 120 Imager.

\section{Western immunoblotting}

Hippocampal tissues were homogenized in TissueProtein Extraction Reagent, TPER (ThermoScientific, \#78510) with protease and phosphatase inhibitor cocktails. The tissue homogenates were sonicated and spun at $13,700 \times g$ at $4{ }^{\circ} \mathrm{C}$ for $30 \mathrm{~min}$. The soluble fraction was diluted with NuPage LDS Sample Buffer and Sample Reducing Agent, run on 4-12\% Bis-Tris Novex NuPage gels (Invitrogen) for $1 \mathrm{~h}$. Proteins were transferred from the gel to PVDF membranes overnight. Membranes were washed and blocked in 5\% milk/PBS blocking buffer and incubated overnight in primary antibodies. Membranes were washed and incubated for $1 \mathrm{~h}$ in corresponding HRP-conjugated secondary antibodies (Jackson ImmunoResearch Laboratories, Inc. \#115-035-146 and \#111035-144). Membranes were incubated with ECL reagent (ThermoScientific) and exposed to X-ray film. Immunoreactive bands on the developed film were scanned and quantified with AlphaEaseFC ${ }^{\mathrm{TM}}$ Software (Alpha Innotech Corporation).

For in vivo experiments: Western blots were probed for phosphorylated tau antibodies: PHF-1 (1:10,000, a generous gift from Dr. Peter Davies); AT180 (1:5000), AT8 $(1: 10,000)$, and total tau Tau5 $(1: 10,000)$ (Thermo Scientific); and activated phospho-p38 MAPK (1:500) and total p38 MAPK (1:1000) (Cell Signaling); and loading control, glyceraldehyde-3-phosphate dehydrogenase (GAPDH) (1:20,000; Millipore).

For in vitro experiments: Western blots were probed for phosphorylated tau antibodies: PHF-1 (1:5,000); AT8 (1:5,000); Tau5 (1:5,000); GAPDH (1:10,000), activated phospho-p38 MAPK (1:500) and total p38 MAPK (1: 1000) (Cell Signaling); and activated phospho-STAT3 and STAT3 (1:2000, Cell Signaling) to verify intracellular neuronal signaling downstream of IL-6.

\section{Immunohistochemistry}

Free-floating sections were processed via standard immunohistochemical methods. Briefly, a sodium citrate solution was used for antigen retrieval, endogenous peroxidases were blocked with $3 \% \mathrm{H}_{2} \mathrm{O}_{2}$ in PBST, and 5\% normal goat serum in Triton/PBS was used as blocking buffer. Primary antibody incubation was overnight at $4^{\circ} \mathrm{C}$. Incubation with corresponding Biotinylated IgG secondary antibodies (Jackson ImmunoResearch Laboratories, Inc. \#115-065-003 and \#111-065-144) was for $1 \mathrm{~h}$. Sections were then incubated with Avidin:Biotinylated enzyme complex reagent and developed using SIGMA$F A S T^{T M}$ 3,3'-Diaminobenzidine (DAB) tablets (Sigma, D4293) without metal enhancer to reveal immunoreactive signals. IHC brain sections were probed for phosphorylated tau, AT180 (1:250, Thermo Scientific), and microglia, ionized calcium-binding adapter molecule 1 (Iba1) (1:500, Wako).

\section{TUNEL assay}

For terminal deoxynucleotidyl transferase dUTP nick end labeling (TUNEL) assay, staining was performed using the protocol supplied with a Roche in situ cell death detection kit (Roche Applied Science \# 11684809910). Sections were co-stained with NeuN (1: 250) (Cell Signaling) to visualize neurons. The percent area of TUNEL+ staining of pyknotic neuronal bodies was imaged and quantified using fluorescent microscopy and threshold analysis in ImageJ.

\section{Quantifying microglia morphology}

ImageJ Skeleton Analysis was based on procedures previously described [31]. Briefly, fixed brain sections were prepared by immunohistochemistry and stained with Iba1, as described above. Brightfield photograph images $(40 \times)$ of Iba1-stained sagittal brain sections were processed into binary skeletonized images using ImageJ with the following steps. First, images were run through a bandpass filter and converted to grayscale, automatic brightness/contrast was applied, followed by the Unsharp Mask filter and Despeckle tools for removing noise. Auto-threshold was applied to create a black and white image contrast of the microglia. An additional despeckle step followed by "binary-close" and "noise-remove outliers" functions (as described in the published protocol) results in removing noise and closing gaps in the microglial processes. Finally, we skeletonize the image using the Skeletonize and Analyze Skeleton functions in Image).

\section{Primary neuron culture and treatments}

Primary neuron cultures were prepared following an established protocol [32]. Briefly, early postnatal (P0-P1) mouse $(\mathrm{C} 57 \mathrm{BL} / 6 \mathrm{j})$ hippocampi and cortices were isolated, rinsed, trypsinized, dissociated and plated on prepared poly-L-lysine coated coverslips. Within two days after plating, cytosine arabinoside (araC; 1-b-d-arabinofuranosylcytosin) is added to inhibit proliferating nonneuronal cells resulting in a predominantly neuronal cell population. Cultures were grown for 16 days in vitro (DIV) at $37^{\circ} \mathrm{C}$ in humidified $5 \% \mathrm{CO}_{2}$ incubator prior to any treatment. DIV 16 cultures were treated with $25 \mathrm{ng} /$ $\mathrm{mL}$ recombinant mouse IL-6 (Biolegend) and collected in LDS/RA solution $12 \mathrm{~h}$ after treatment. Collected cell 
lysates in LDS/RA were sonicated and boiled before use in western immunoblot assay.

\section{Adult neuron isolation and treatments}

Dissociation of adult mouse brains was performed using the "Adult Brain Dissociation Kit for mouse and rat" (Miltenyi Biotec, 130-107-677) and "Neuron Isolation Kit for mouse" (Miltenyi Biotec, 130-115-389) following the user manual, in combination with the gentleMACS Dissociator (Miltenyi Biotec). Mice were anesthetized and the brains removed then cut into 8 sagittal slices. Brain slices were homogenized using the gentle MACS Dissociator in C Tubes (Miltenyi Biotec, 130-093-237) with the recommended volume of enzyme mixes. Tissue was processed with no modification to the protocol in the kit. Isolated neurons from the adult mouse brains were cultured for one week changing half the media (MACS Neuro Medium containing 2\% MACS Neuro Brew-21,1\% penicillin/streptomycin, and $0.5 \mathrm{mM} \mathrm{L-glu-}$ tamine) every other day. One week after neuronal isolation, neurons were treated with $25 \mathrm{ng} / \mathrm{mL}$ recombinant mouse IL-6 (Biolegend) and collected in LDS/RA solution $12 \mathrm{~h}$ after treatment. Collected cell lysates in LDS/ RA were sonicated and boiled before use in western immunoblot assay.

\section{Statistics}

Unless otherwise indicated, comparisons between the two groups were done via unpaired $t$ test. Comparisons between multiple treatment groups were done via one-way or two-way analysis of variance (ANOVA) with Sidak's multiple comparison post hoc test. All statistical analyses were performed using GraphPad Prism ${ }^{\bullet}$ Version 8).

\section{Results}

\section{Genetic deletion of II10 promotes tau}

hyperphosphorylation after peripheral LPS administration Abnormal hyperphosphorylation of tau is regarded as an early hallmark of AD [33, 34]. Well-characterizedADrelevant phosphorylated tau epitopes at Ser202/Thr205, Thr231, and Ser396/Ser404 detected by AT8, AT180, and PHF-1 antibodies, respectively, can serve as markers for tau pathology [35-37]. Protein analysis via Western blot of hippocampal lysates from $1 l 10^{-1-}$ and Non-Tg mice was performed to determine the levels of tau phosphorylation at AT8, AT180, and PHF-1 epitopes 24 $\mathrm{h}$ following one dose of intraperitoneal LPS injection (Fig. 1A-D). No significant differences were found in the basal levels of phosphorylated tau (pTau) or total tau between $I l 10^{-/-}$and Non-Tg mice treated with Veh. However, $24 \mathrm{~h}$ following LPS-injection, both the $1110^{-/-}$ and Non-TgLPS-treated groups had increased AT8+ and AT180+ pTau. Importantly, the $I l 10^{-/-}$LPS mice had significant increases in AT8+, AT180+, and PHF-1+
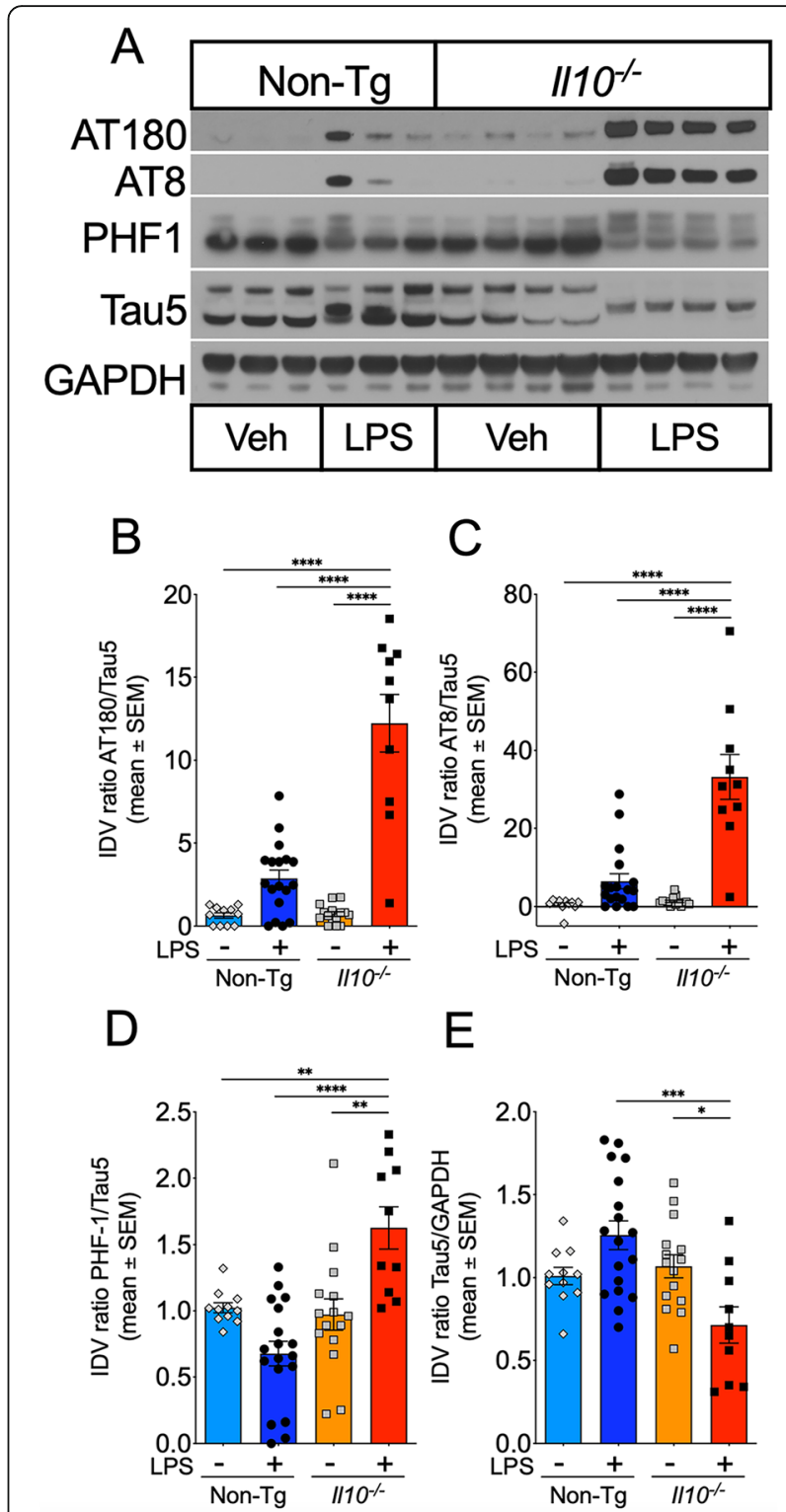

E

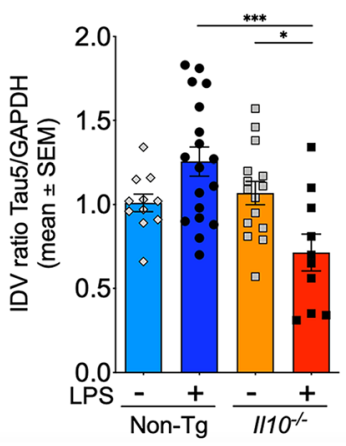

Fig. 1 Genetic deletion of $/ 110$ promotes tau hyperphosphorylation after LPS injection. Non-Tg or $1 / 10^{-1-}$ mice injected with LPS or Veh were sacrificed $24 \mathrm{~h}$ after LPS injection and brain tissue was extracted for analysis. A Western immunoblot (WB) of hippocampal (Hp) homogenates to assess levels of phosphorylated AT8, AT180, and PHF1 tau epitopes. Glyceraldehyde 3-phosphate dehydrogenase (GAPDH) was analyzed as a protein loading control. B-D Quantification of immunoreactive bands as a ratio of pTau (AT180, AT8, and PHF-1) over total tau (Tau5). E Quantification of immunoreactive bands as a ratio of Tau5 over GAPDH. Data shown are mean + SEM of integrated density value (IDV) ratio; ${ }^{*} p<0.05$, ${ }^{* *} p<0.01,{ }^{* * *} p<0.001$; two-way ANOVA with Sidak's multiple comparison test; $n=10-18$ mice; each individual data point shows an individual mouse sample

pTau compared to the Non-Tg LPS mice (Fig. 1B-D). Notably, total tau levels were significantly reduced in $I l 10^{-1-}$ mice after LPS administration (Fig. 1E) compared to $I l 10^{-1-}$ Veh mice and Non-TgLPS-treated mice. These 
data suggest that deficiency of IL-10 exacerbates hyperphosphorylation of tau in the hippocampus within $24 \mathrm{~h}$ of LPS administration.

To verify the spatial distribution of phosphorylated tau in different sub-regions within the dentate gyrus of the mouse brains, immunohistochemistry (IHC) of sagittal brain sections was performed. Quantification of AT180+ area, $24 \mathrm{~h}$ post-LPS treatment, confirmed significantly enhanced pTau in the dentate gyrus of $1 l 10^{-/-}$mice compared to Non-Tg mice (Fig. 2A, B). The morphology of the AT180+ area resembled neuronal cell bodies rather than astrocytes or oligodendrocytes, which can also abnormally harbor pTau [38-40]. These results confirm significantly increased phosphorylated tau epitopes in hippocampal neurons of $1 l 10^{-/-}$mice.

LPS-treated $1110^{-/-}$mice show signs of neurodegeneration We speculated that a loss of total tau mentioned above is most likely due to neuronal death since tau is highly enriched in neurons [4]. To evaluate the possibility of neuronal cell death within the hippocampi of the LPSinjected mice, neuronal cell death was examined using
TUNEL assay. There was notable detection of TUNEL positive cells (green) colocalized with $\mathrm{NeuN}+$ neurons (red) that appeared to have yellowish nuclei (arrows) in the CA3 hippocampal regions of $I l 10^{-1-}$ LPS mice compared to the Veh and Non-Tg LPS groups (Fig. 2C). Quantification confirmed the increased number of TUNEL+ cells in the neuronal layer of $1 l 10^{-1-}$ LPS mice compared to the Veh and Non-Tg LPS groups (Fig. 2D). These data corroborate neuronal cell death in $\mathrm{IllO}^{-/-}$ LPS mice, which is consistent with the significant reduction in neuron-enriched tau protein.

\section{I/10deficiency enhances LPS-induced p38 MAPK activation}

Activated p38 MAPK is a member of the MAPK family and key signal transduction protein involved in CNS inflammation [41] and implicated in tau phosphorylation [12, 42-46]. To determine if activated p38 MAPK was elevated in the $1 l 10^{-1-}$ mice, we examined levels of phosphorylated p38 MAPK (phospho-Thr180/Tyr182) in the hippocampal lysates (Fig. 3). Basal levels of phospho-p38 were no different in $I l 10^{-/-}$mice vs NonTg mice and LPS administration did not significantly

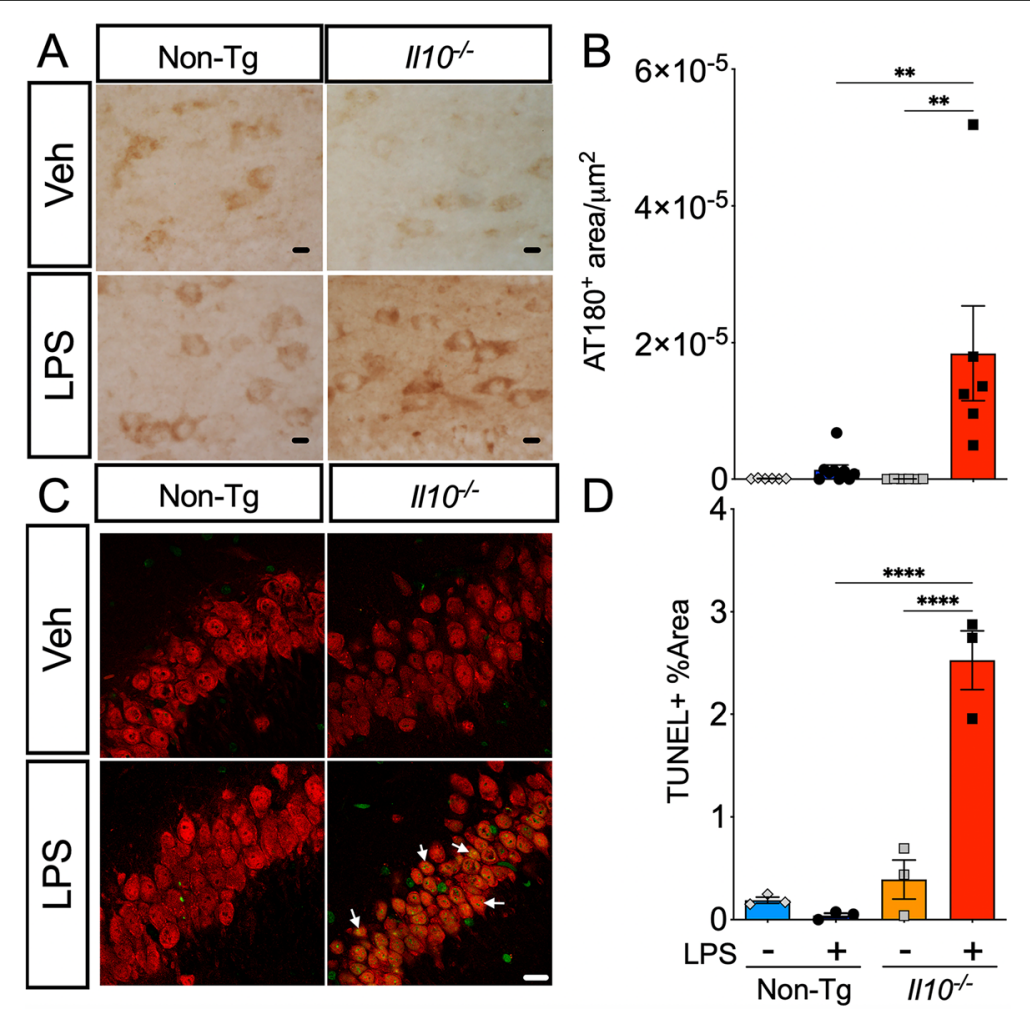

Fig. 2 LPS-treated $/ / 10^{-/-}$mice have increased neuronal p-tau and increased neuronal apoptotic cell death. Brain sections from Non-Tg or $/ 110^{-/-}$mice described above. A, B Immunohistochemistry (IHC) for endogenous pTau probed with AT180 antibody; 40x magnification; scale bar $=10 \mu \mathrm{m}$. A Representative sections from the dentate gyrus (DG) region of interest (ROI). B Quantification of AT180+ area. Data shown are mean \pm SEM of area/ $\mu \mathrm{m}^{2}$ from the standardized averages of three repeat trials; ${ }^{*} p<0.05,{ }^{* *} p<0.01$, ${ }^{* * *} p<0.001$; two-way ANOVA with Sidak's multiple comparison test; $n=4-9$ mice/group. C, D TUNEL immunofluorescence assay co-stained with NeuN antibody (arrows) to identify neurons in the Hp CA3 region; 63X magnification; scale bar $=10 \mu \mathrm{m}$. D Quantification of TUNEL+ area (green). Data shown are mean \pm SEM of $\%$ area TUNEL+ cells in CA3 ROI; * $p<$ $0.05,{ }^{* *} p<0.01 ;{ }^{* *} p<0.001 ; 2$-way ANOVA; $n=3$ mice/group; each individual data point shows an individual mouse sample 

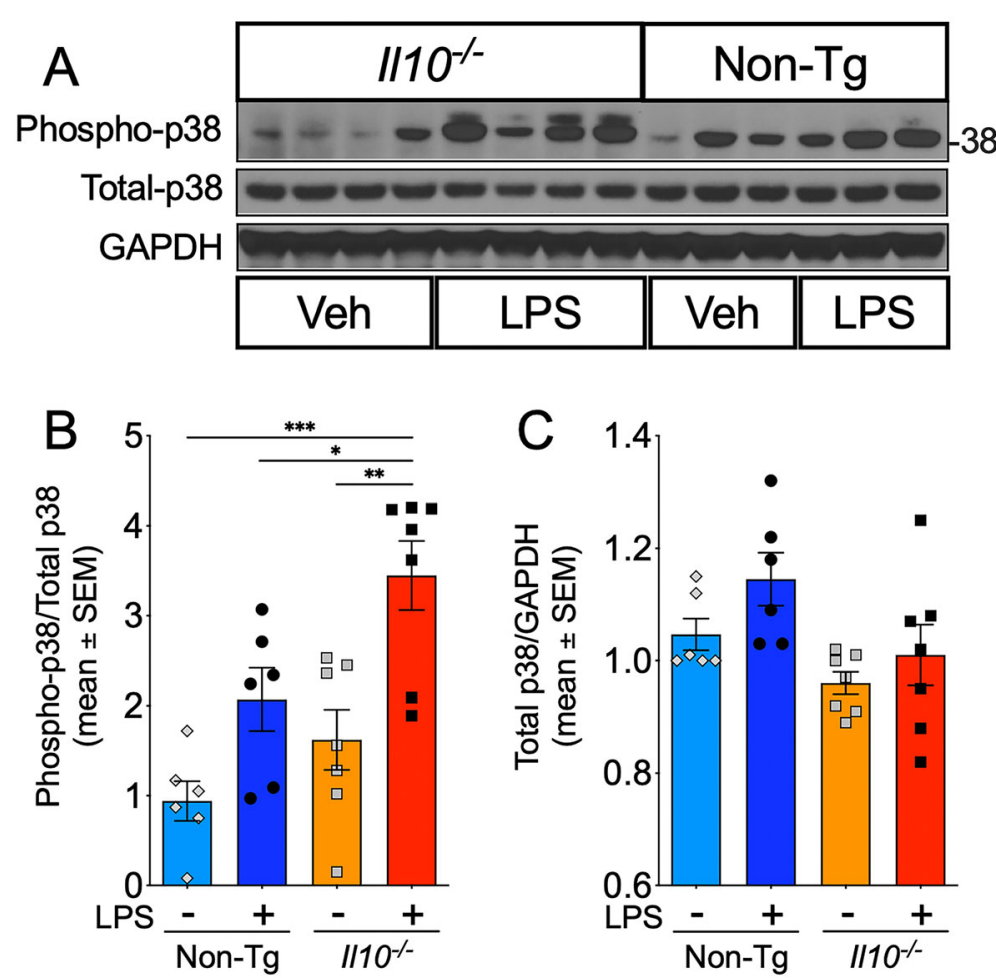

Fig. 3 //10 deficiency significantly enhances p38 MAPK activation after LPS injection. WB of Hp homogenates from Non-Tg or $/ 110^{-/-}$mice described above. A Levels of (activated) phospho-p38 MAPK relative to (total) p38 MAPK; GAPDH protein loading control. Each lane represents an individual mouse sample. B, C Quantification of immunoreactive bands as ratio of phospho-p38 over total-p38 (B) and total-p38 relative to GAPDH (B). Data shown are mean \pm SEM of IDV ratio; * $p<0.05 ;{ }^{* *} p<0.01$; *** $p<0.001$; two-way ANOVA with Sidak's multiple comparison test; $n=6-7$ mice/group

elevate levels of active p38 MAPK in LPS-injectedNonTg mice (Fig. 3A, B). However, robust and statistically significant phospho-p38 MAPK activation was observed in LPS-injected $l l 10^{-1-}$ mice compared to the LPSinjectedNon-Tg control group (Fig. 3A, B). No statistically significant differences in the total p38 ratio over GAPDH were observed in either genotypes or treatment groups when assessed by two-way ANOVA (Fig. 3C). These data suggest IL-10 deficiency alters active forms of p38 MAPK and, in the context of an inflammatory response, correlates with enhanced tau phosphorylation and neurodegeneration.

\section{II10-deficient microglia display activated morphology with LPS treatment}

Next, we wanted to assess the microglial phenotype in $\mathrm{IllO}^{-1-}$ mice after LPS administration to reassert the role of reactive microglia in driving pTau. Brain sections were stained with Iba1 to visualize microglial morphology (Fig. 4A) and a skeleton analysis was performed to quantify the branching (data not shown) and junctions of microglial processes in the hippocampus (Fig. 4B). We observed that $I l 10^{-1-}$ Veh mouse brains already had a slightly elevated, though not statistically significant, Iba1+ area compared to Non-Tg Veh controls. Interestingly, the $I_{110^{-1-}}$ Veh microglia in the CA1 region had slightly increased branching (data not shown) and significantly increased the number of junctions compared to the other groups (Fig. 4D). After LPS administration, we observed that the Iba1+ area increased in both groups, suggesting a more activated phenotype than vehicle-treated respective control (Fig. 4C). Notably, there was no significant enhancement of Iba1 expression attributed to IL-10 deficiency after LPS administration. However, analysis of the skeletonized branching of the microglia revealed that $1110^{-/-}$microglia had significantly reduced branching (data not shown) and decreased the number of junctions compared to NonTg microglia post-LPS (Fig. 4D). This suggests a more amoeboid, highly activated phenotype resembling proinflammatory microglia in the LPS-treated $/ l 10^{-/-}$mice brains compared to LPS-treatedNon-Tg controls.

\section{II10 deficiency significantly enhanced inflammatory cytokines}

Cytokine levels in cortical tissue lysates from $\mathrm{Il1O}^{-1-}$ and Non-Tg mouse brains were examined to confirm the pro-inflammatory phenotype. First, basal levels of IL-10 were below the level of detection in both groups prior to 

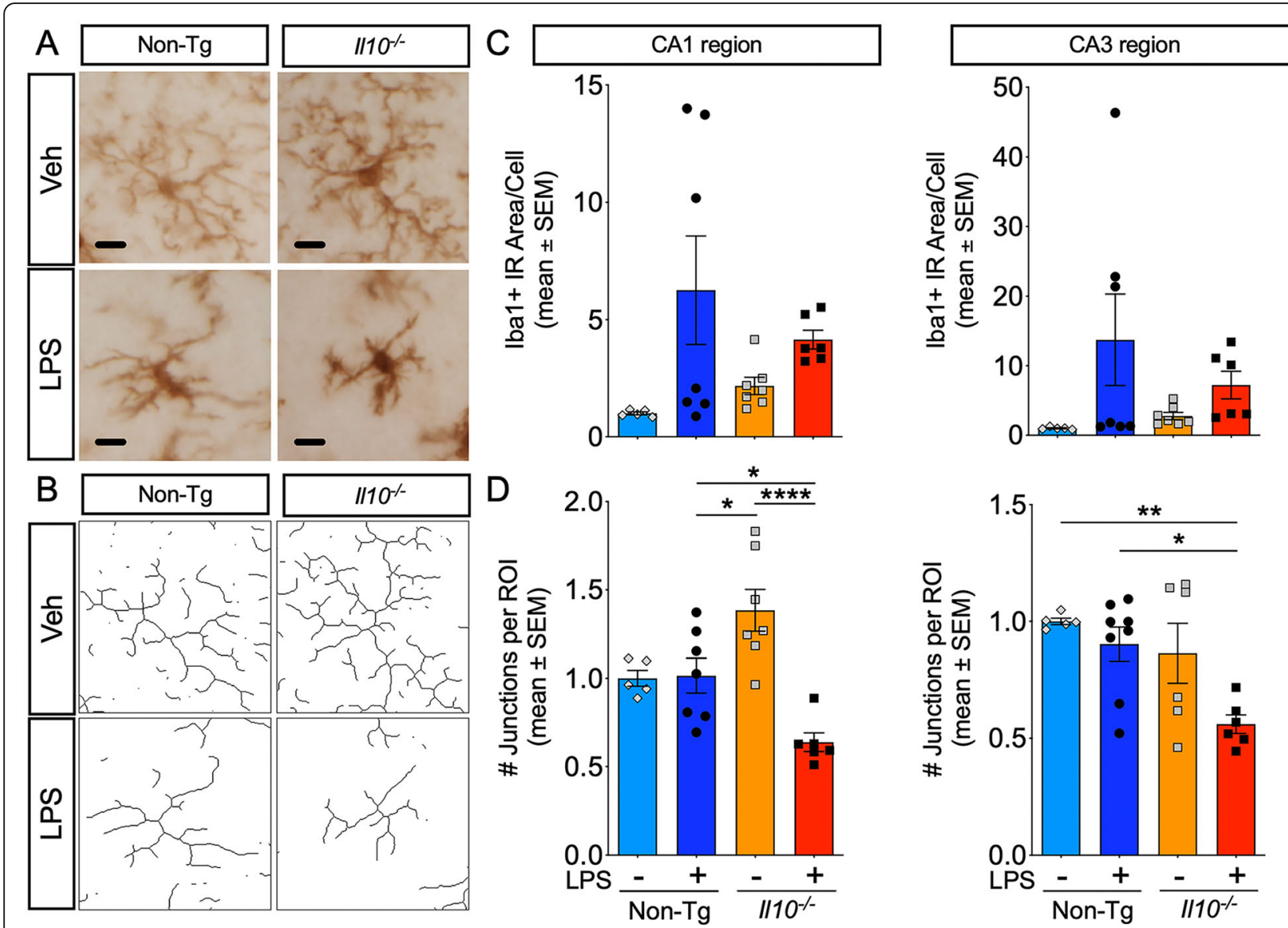

Fig. 4 //10 deficiency promotes a proinflammatory microglia morphology after LPS injection. IHC to visualize microglial morphology in CA1 and CA3 regions from Non-Tg or $1110^{-/-}$mice described above; $40 \times$ images were quantified; scale bar $=10 \mu \mathrm{m}$. A Representative Iba1+ microglia from CA1 ROI. B Representative skeletonized microglia (derived from A). C, D Quantification of Iba1+ immunoreactive (IR) area (C) and the number of junctions per ROI (D). Data shown are mean \pm SEM of normalized values; ${ }^{*} p<0.05,{ }^{* *} p<0.01$; ${ }^{* * *} p<0.001$; two-way ANOVA with Sidak's multiple comparison test; $n=5-7$ mice/group. Each individual data point represents an individual mouse sample

LPS. Basal levels of IL-12, IL-1 $\beta$, and TNF $\alpha$ were low and not significantly different in $1 l 10^{-/-}$mice vs Non-Tg controls. Slightly elevated levels of IL-10 were still detectable in a number of LPS-treatedNon-Tg mice $24 \mathrm{~h}$ after the LPS challenge whereas IL-10 remained below background levels of detection in LPS-treated $I l 10^{-/-}$ mice (Fig. 5A). Additionally, the Non-Tg group had elevated levels of IL-1 $\beta$, TNF $\alpha$, and IL- 6 after LPS administration (Fig. 5C-E). In comparison, $\mathrm{IllO}^{-/-}$mice had significantly enhanced levels of IL-12, TNF $\alpha$, and IL-6 relative to Non-Tg controls (Fig. 5B, D, E). Out of all four pro-inflammatory cytokines studied, a thousandfold elevated increase in IL-6 levels that remained elevated at $24 \mathrm{~h}$ post-LPS injection in LPS-treated $I l 10^{-/-}$ mice was very striking (Fig. $5 \mathrm{E}$ ). Surprisingly, IL-1 $\beta$ was not found to be significantly elevated in the LPS $1 l 10^{-/-}$ mice compared to LPS-treatedNon-Tg controls at this 24 h timepoint (Fig. 5B).

\section{Direct stimulation of primary neurons with IL-6 induces} tau hyperphosphorylation

Since IL-6 was expressed by more than a thousand-fold increase in LPS-treated $I l 10^{-/-}$mice compared to LPStreatedNon-Tg controls, we evaluated the potential role of IL- 6 on tau phosphorylation in murine primary neurons. First, we treated mouse primary neuronal cultures derived from P0 C67BL/6j pups with recombinant IL-6 and performed Western blot analysis for phospho-tau in the cell lysates. We verified that activated STAT3 (phospho-tyr705) levels were significantly elevated in IL6-treated neurons (Fig. 6A-D) indicating expected intracellular response downstream of IL-6 signaling. Next, we observed a modest increase in the AT8/Tau5 and AT8/ GAPDH ratios in IL-6-treated neurons compared to vehicle-treated controls. Importantly, PHF-1/Tau5 and PHF-1/GAPDH ratios were significantly higher in IL-6 stimulated neurons relative to Veh controls (Fig. 6A-D). 


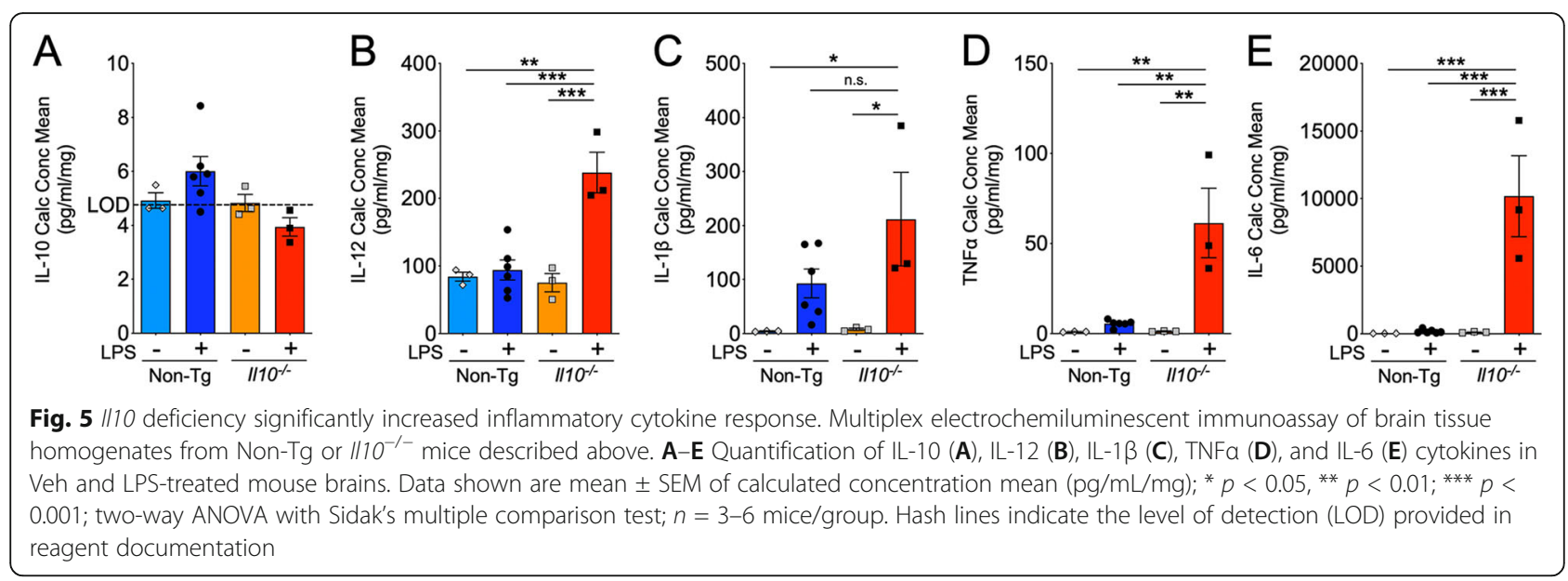

Interestingly, similar to the trends we observed with the in vivo results, there was a modest reduction in total tau (Tau5/GAPDH ratio) and an increase in p-p38/total-p38 MAPK ratio in the IL6-treated neurons (Fig. 6A-D). Furthermore, stimulation of neurons derived from adult IL-10 knockout mice with IL-6 showed significantly elevated levels of PHF-1/Tau5 ratio compared to adult non-transgenic neurons treated with IL-6 (Fig. 6E-F). This suggests that IL- 6 is sufficient to promote increased tau phosphorylation within neurons and it is enhanced in neurons deficient in IL-10.

\section{Discussion}

In this study, we demonstrate that deficiency of IL-10 was sufficient to increase tau hyperphosphorylation after only $24 \mathrm{~h}$ of a moderate dose of LPS treatment. We observed tau phosphorylation was enhanced in $I l 10^{-/-}$ mice treated with LPS. We detected reduced total tau

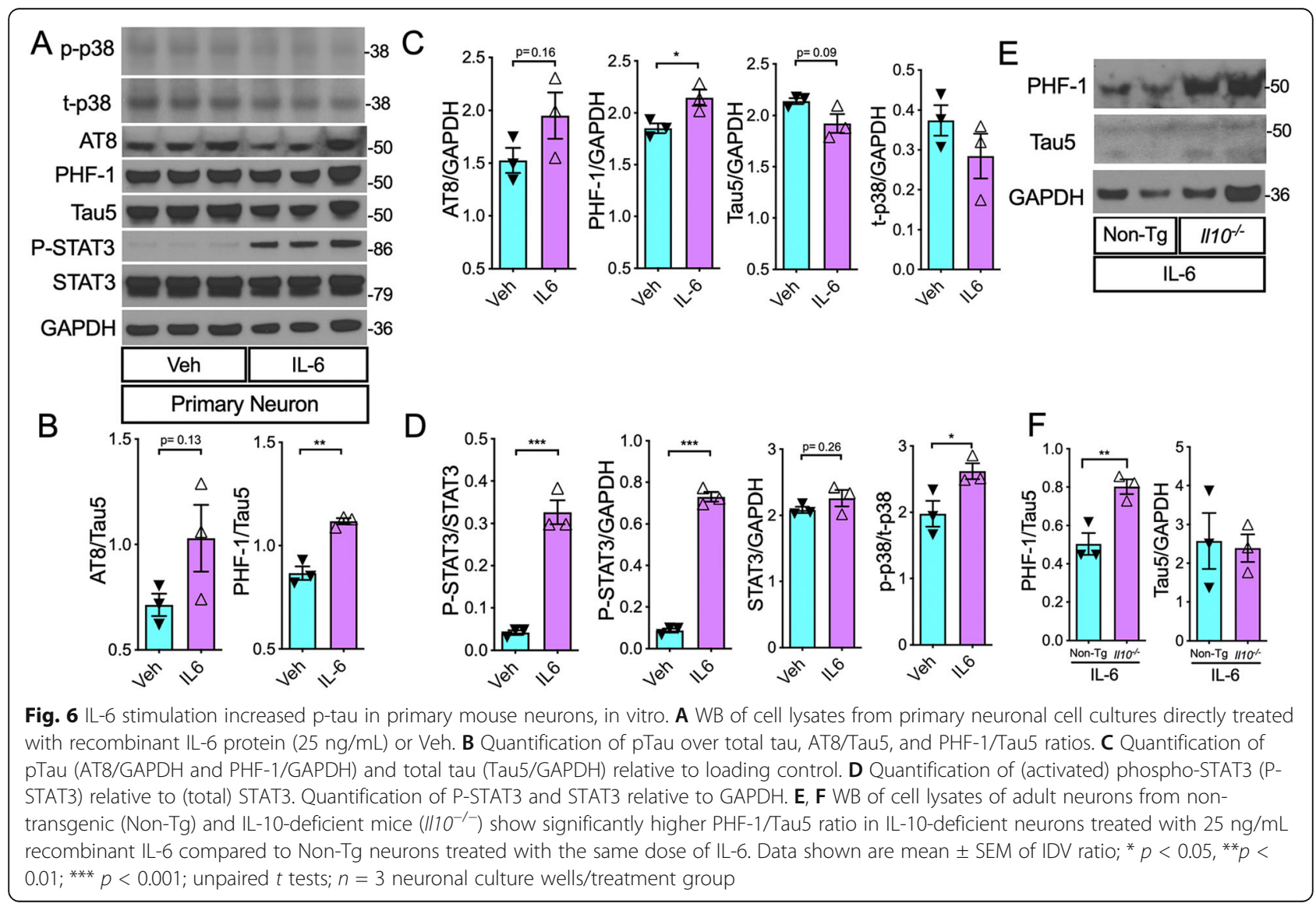


and increased neuronal cell death in hippocampi of LPStreated $l l 10^{-1-}$ mice. We confirmed that an important tau kinase, p38 MAPK, was activated in hippocampal tissue of $I l 10^{-1-}$ mice after LPS administration and significantly enhanced in the LPS-treated $l l 10^{-1-}$ mice compared to LPS-treatedNon-Tg controls. $\mathrm{IllO}^{-/-}$microglia had morphological features of activated amoeboid cells, along with upregulation of pro-inflammatory cytokines, IL-12, TNF $\alpha$, and IL-6, after LPS treatment. Particularly, IL-6 was substantially increased in the LPS-treated $I l 10^{-/-}$ mice and we demonstrated that direct stimulation with IL-6 is sufficient to induce tau phosphorylation in a primary mouse neuronal culture. These data substantiate a role for IL-10 in regulating the inflammatory response to an immune challenge through TLR4 signaling that involves p38 MAPK, microglial activation, and excessive pro-inflammatory cytokine expression, which results in hyperphosphorylation of tau.

IL-10 dysregulation is highly relevant to $\mathrm{AD}$ in a number of ways. First, there are single nucleotide polymorphisms (SNPs) in the $I l 10$ promoter associated with increased risk of $\mathrm{AD}[22,47]$. For example, the ATA haplotype $(-1082 \mathrm{~A} /-819 \mathrm{~T} /-592 \mathrm{~A})$ of the IL-10 gene promoter region is associated with susceptibility to $\mathrm{AD}$ [20, 48]. Particularly, an "A" allele at position 1082 has been associated with low production of IL-10 [49] and is implicated in promoting mild cognitive impairment (MCI) to $\mathrm{AD}[19,47]$. In line with the association of low IL-10 production with $\mathrm{AD}$, patients with faster rates of decline in their mini-mental state exams (MMSE) were shown to have significantly lower production of IL-10 upon ex vivo peripheral blood mononuclear cell (PBMC) stimulation, suggesting that IL-10 expression could be protective in the slow declining population [50]. Our study corroborates the concept of IL-10 dysfunction leading to an increased pathology related to AD.

Second, IL-10 regulates microglial phenotype and immune processes, which are implicated in AD. According to a recent genome-wide association study (GWAS) by the International Genomics of Alzheimer's Project, some of the most influential risk factors for AD compared to controls were in genotypes associated with microglia and the immune system [51, 52]. Furthermore, animal studies have shown that reactive microglia are sufficient to drive tau pathology $[12,53]$ but the role of pro- and anti-inflammatory mediators on microglial phenotype and function is still being understood. Dysregulated IL10 expression has been shown to alter microglial phenotype through both overexpression and deficiency $[54,55]$ but there are still conflicting data on how IL-10 influences microglial function. For example, in the context of amyloid plaque clearance, it has been shown that IL-10 dampens $\beta$-amyloid clearance and IL-10 deficiency permits $\beta$-amyloid phagocytosis by microglia $[24,56]$.
On the other hand, a recent in vitro study suggests that IL-10 promotes phagocytosis dependent on the triggering receptor expressed on myeloid cells 2 (TREM2) in microglia [57]. IL-10 deficiency, in our LPS model, promoted a highly activated, pro-inflammatory microglial phenotype. Interestingly, the microglia in our Vehtreated $l l 10^{-/-}$mice, which are deficient in IL-10 throughout their life, seemingly had an intermediate stage of activation (increased Iba1 and hypertrophic processes) in the hippocampus CA1, but not the CA3, region. Thus, discerning the effects of dysregulated IL-10 on $\mathrm{AD}$ may require an understanding of intermediate activation states of microglia, the microglial microenvironment, and the dosage as well as the timing of IL- 10 .

Finally, dysregulation of cytokines, including IL-10, is implicated in AD. For example, inflammasome signaling molecules are increased in AD brains [58] and colocalize with microglia around plaques [8]. Furthermore, patients with advanced rates of progression from $\mathrm{MCI}$ to dementia in AD have elevated levels of pro-inflammatory cytokines in the CSF [59]. Although IL-10 is also found to be upregulated in the CSF of AD patients [60], it is concomitant with elevation in pro-inflammatory cytokine levels. This is in line with the role of IL-10 in negative feedback inhibition in response to inflammatory stimuli $[17,61]$. On the same note, we saw that the absence of IL-10 lead several cytokines, including TNF $\alpha$ and IL-6, to run rampant after the LPS challenge. IL-10 signaling through the IL-10 receptor in microglia involves activation of the JAK/STAT/SOCS pathway [62] resulting in IL-10 induced genes. This includes dual-specificity phosphatases (DUSP), which downregulates p38 MAPK activation in myeloid cells $[63,64]$. In line with this, we saw that the absence of IL-10 lead to increased p38 MAPK activation. IL-10 has been shown to regulate the expression of a number of pro-inflammatory cytokines in microglial cultures and brain tissue $[15,65,66]$. This includes IL-1 $\beta$, which can peak at $5 \mathrm{~h}$ in the brain after peripheral LPS administration in rodents [66] but has complex endotoxin-dependentIL-1 $\beta$ maturation kinetics depending on extracellular ATP release [67]. Interestingly, we observed that IL-1 $\beta$ cytokine expression did not remain significantly elevated in $I l 10^{-/-}$mice compared to Non-Tg mice at $24 \mathrm{~h}$ after LPS administration. This may suggest another compensatory mechanism limited the ongoing expression of IL-1 $\beta$ within $24 \mathrm{~h}$ in our model. However, we do not know the relative expression levels of IL-1 $\beta$ at earlier timepoints and cannot rule out a role for IL-1 $\beta$ in promoting tau hyperphosphorylation in this model. Potentially, there are multiple routes leading to $\mathrm{AD}$-relevant tau phosphorylation if left unregulated. In our study, TNF $\alpha$ and IL-6, were particularly elevated by LPS in the absence of IL-10. Interestingly, IL-6 remained significantly elevated in the $1 l 10^{-/-}$ 
mice, which alludes to clinical correlations between genotypes associated with low IL-10 and high IL-6 production as a risk factor for $\mathrm{AD}[21,68,69]$. Therefore, we explored the potential for IL- 6 to promote tau phosphorylation in neurons by directly stimulating neuronenriched primary cultures with recombinant IL-6.IL-6 stimulation was sufficient to induce tau phosphorylation in primary hippocampal neurons consistent with a previous study that showed IL-6 stimulation increased neuronal pTau [70]. Interestingly, the study by Quintanilla et al., showed that treatment of primary hippocampal rat neurons with $5 \mathrm{ng} / \mathrm{mL}$ IL-6 significantly increased phosphorylated tau (AT8/Tau5 ratio) and lowered unphosphorylated tau (Tau1/Tau5 ratio) after a 48-h incubation. In our study, treatment of primary hippocampal mouse neurons with $25 \mathrm{ng} / \mathrm{mL}$ of IL- 6 for $12 \mathrm{~h}$ significantly increased tau phosphorylation on the Ser396/Ser404 (PHF-1) epitope and total tau (Tau5/ GAPDH) was significantly decreased. These data support a role for dysregulated cytokines, including IL-10 and IL-6, in promoting AD-relevant tau phosphorylation. It is important to note that our results do not show elevated cytokine levels in IL-10 knockout mice with LPS is cell-autonomous to microglia. As such, at this stage, it is still correlational and require single cell RNA sequencing and profiling of microglia based on their cytokine expression phenotype. Performing such studies is beyond the scope of the present study and our future studies will determine if disease-associated microglia (DAMs), interferon-responsive microglia (IRMs), and other types of microglia relevant to $\mathrm{AD} /$ tauopathies are specifically altered in IL-10 knockout mice brains with LPS challenge.

The role that inflammation plays and whether it contributes to $\mathrm{AD}$ has increasingly become an important area of research due to increased evidence that microglial activation and abnormal expression of cytokines are associated with $\mathrm{AD}$. Understanding inflammatory pathways that promote tauopathy is necessary to find novel targets for AD. Here, we provide evidence that IL-10 deficiency enhances a pro-inflammatory environment in the brain after a peripheral immune challenge leading to hyperphosphorylation of tau on AD-relevant epitopes. Our model involves inducing inflammation through TLR4 signaling using LPS as the stimulus. Immune activation through TLR4 is relevant in $A D$ as amyloid beta $(A \beta)$, is known to trigger TLR4 signaling to secrete inflammatory factors [71, 72]. TLR4 can also be triggered by danger-associated molecular patterns (DAMPs) due to neuronal injury and other tissue damage [73]. Therefore, this model pertains to TLR4 signaling promoting tauopathy and is not strictly pertinent to immune response due to infection. Moreover, several recent reports implicate the endotoxin hypothesis driving neurodegeneration [74-76]. Whether the moderate dose of peripheral LPS used in our study leads to direct TLR4

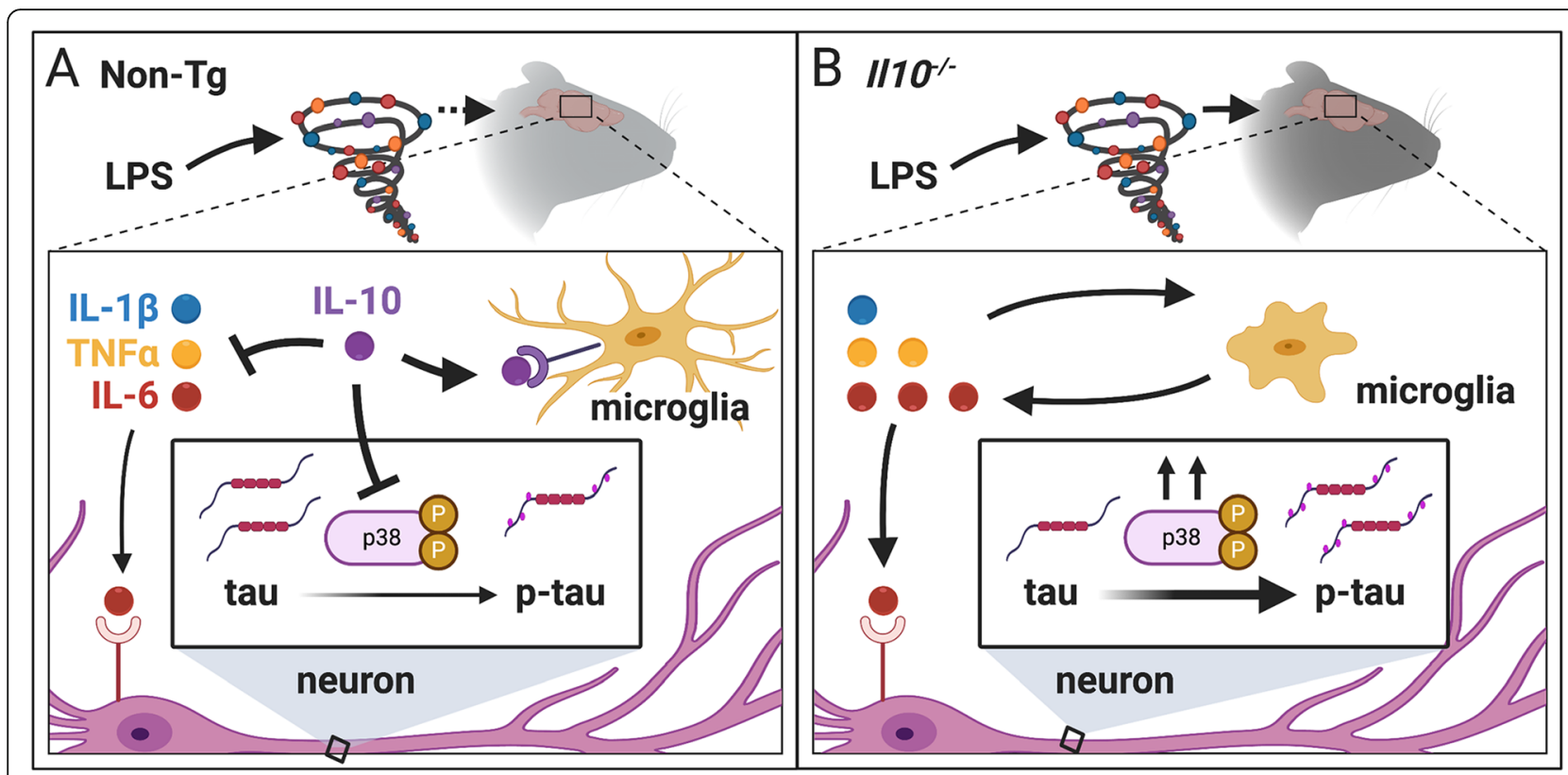

Fig. 7 Proposed model for IL-10 regulation of neuroinflammation and tau pathology. A In non-transgenic (Non-Tg) mice, we observed an increase in proinflammatory cytokines, including IL-6, TNFa, and IL-1 $\beta$, with a concomitant increase in anti-inflammatory cytokine, IL-10. IL-10 provides negative feedback to dampen cytokine production, microglial activation, and p38 MAPK activation resulting in only low levels of tau phosphorylation. B In IL-10-deficient mice $\left(\| 10^{-/-}\right)$, the absence of IL-10 leads to enhanced cytokine production, especially for IL-6 and TNF, microglia are more active and more amoeboid, and p38 MAPK levels are also enhanced. Tau phosphorylation is exacerbated in neuronal bodies of the $1110^{-1-}$ brains. Created with BioRender.com 
stimulation within the brain parenchyma or induces a cytokine storm to trigger brain inflammation, the result in our study is that microglia become highly activated and the brain is flooded with pro-inflammatory molecules that persist after $24 \mathrm{~h}$ in IL-10-deficient mice. Our data is consistent with a model (Fig. 7), whereby IL-10 has an important role in limiting an ongoing inflammatory response leading to tau hyperphosphorylation relevant to AD.

\section{Conclusions}

Our study shows that IL-10 deficiency is sufficient to promote tau hyperphosphorylation and dysregulated neuroinflammation in the context of an acute peripheral inflammatory insult. Genetic deletion of $I l 10$ promoted enhanced pro-inflammatory cytokine expression, activated microglial morphology, and evidence of neuronal loss. Exacerbated neuroinflammation in the IL-10deficient environment corresponded with increased taukinase p38 MAPK activation and significantly increased tau phosphorylation. These data support the significance of IL-10 in modulating pro-inflammatory microglial activation, dysregulated cytokine production, and hyperphosphorylation of AD-relevant tau epitopes.

\section{Abbreviations}

AD: Alzheimer's disease; CNS: Central nervous system; DG: Dentate gyrus; GAPDH: Glyceraldehyde 3-phosphate dehydrogenase; Hp: Hippocampus; Iba1: Ionized calcium-binding adapter molecule 1; IDV: Integrated density value; IHC: Immunohistochemistry; IL-1 $\beta$ : Interleukin-1 $\beta$; IL-10: Interleukin-10; I/10-1-: /I10-deficient mice; IL-12: Interleukin-12; IL-6: Interleukin-6; IR: Immunoreactive; LOD: Level of detection; LPS: Lipopolysaccharide; MAPT: Microtubule-associated protein tau; MCl: Mild cognitive impairment; MMSE: Mini-mental state exams; MSD: Meso Scale Discovery multiplex; NeuN: Neuronal nuclei; Non-Tg: Non-transgenic; PBMC: Peripheral blood mononuclear cell; p38-MAPK: p38 mitogen-activated protein kinase; p38aMAPK: p38 mitogen-activated protein kinase type a; p-Tau: Hyperphosphorylated tau; SNP: Single nucleotide polymorphism; SOCS: Suppressor of cytokine signaling; TLR4: Toll-like receptor 4; TREM2: Triggering receptor expressed on myeloid cells 2; TNF-a: Tumor necrosis factor $a$;

TUNEL: Terminal deoxynucleotidyl transferase dUTP nick end labeling

\section{Acknowledgements}

We thank Dr. Erin Milligan for providing the initial set of $1 / 10^{-/-}$mice for preliminary data. Ms. Tracylyn Yellowhair for providing professional support with MSD experiments. Mr. Akshay Warrier for laboratory assistance as a trainee. Dr. Jason Weick and Dr. Praveen Chander for primary neuronal culture training. Dr. Sharina Desai for training at the AIM CoBRE. Dr. Michael Paffett for training and assistance at the UNM Cancer Center Fluorescence Microscopy Shared Resource facility.

\section{Authors' contributions}

LW and KB designed the study. LJ provided technical guidance. LW, SJ, DC and $L J$ performed research. LW and KB analyzed data and contributed to manuscript preparation. LW wrote the manuscript. All authors read and approved the final manuscript.

\section{Funding}

This work was primarily funded by the Infectious Disease and Inflammation Program pre-doctoral T32 training grant, NIH/NIAID T32AI007538 (to LW). Additional support was from R01NS083704 and 2RF1NS083704-05A1 (to KB), University of New Mexico Stephanie Ruby Predoctoral Travel Award and Brain \& Behavioral Health Institute mini-grant (to LW), and Autophagy Inflammation and Metabolism (AIM) Center for Biomedical Research Excellence (CoBRE) NIH grant P20GM121176 (to Dr. Vojo Deretic). This research made use of the Fluorescence Microscopy and Cell Imaging Shared Resource which is partially supported by UNM Comprehensive Cancer Center Support Grant NCI P30CA118100.

\section{Availability of data and materials}

The datasets used and/or analyzed during the current study are available from the corresponding author on reasonable request.

\section{Declarations}

Ethics approval and consent to participate

All animal experiments performed in this study were in accordance with the ethical standards of the Institutional Animal Care and Use Committee at the University of New Mexico.

\section{Consent for publication \\ Not applicable}

\section{Competing interests}

The authors declare that they have no competing interests.

\section{Author details}

${ }^{1}$ Department of Molecular Genetics and Microbiology, University of New Mexico, MSC08 4660, 1 University of New Mexico, Albuquerque, NM 87131, USA. ${ }^{2}$ Department of Pediatrics, Johns Hopkins University School of Medicine, Baltimore, MD 21287, USA. ${ }^{3}$ Department of Neurology, University of New Mexico, 1 University of New Mexico, Albuquerque, NM 87131, USA.

Received: 12 December 2020 Accepted: 4 July 2021

Published online: 18 July 2021

\section{References}

1. Lee G, Leugers CJ. Tau and tauopathies. Prog Mol Biol Transl. 2012;107:26393. https://doi.org/10.1016/B978-0-12-385883-2.00004-7.

2. Morris M, Maeda S, Vossel K, Mucke L. The many faces of tau. Neuron. 2011; 70(3):410-26. https://doi.org/10.1016/j.neuron.2011.04.009.

3. Buée L, Bussière T, Buée-Scherrer V, Delacourte A, Hof PR. Tau protein isoforms, phosphorylation and role in neurodegenerative disorders11These authors contributed equally to this work. Brain Res Rev. 2000;33(1):95-130. https://doi.org/10.1016/S0165-0173(00)00019-9.

4. Lee V, Goedert M, Trojanowski JQ. Neurodegenerative tauopathies. Annu Rev Neurosci. 2001;24(1):1121-59. https://doi.org/10.1146/annurev. neuro.24.1.1121

5. O'Leary JC, Li Q, Marinec P, Blair LJ, Congdon EE, Johnson AG, et al. Phenothiazine-mediated rescue of cognition in tau transgenic mice requires neuroprotection and reduced soluble tau burden. Mol Neurodegener. 2010; 5(1):45. https://doi.org/10.1186/1750-1326-5-45.

6. Nelson PT, Alafuzoff I, Bigio EH, Bouras C, Braak H, Cairns NJ, et al. Correlation of Alzheimer disease neuropathologic changes with cognitive status: a review of the literature. J Neuropathol Exp Neurol. 2012;71(5):36281. https://doi.org/10.1097/NEN.0b013e31825018f7.

7. Schöll M, Lockhart SN, Schonhaut DR, O'Neil JP, Janabi M, Ossenkoppele R, et al. PET Imaging of tau deposition in the aging human brain. Neuron. 2016;89(5):971-82. https://doi.org/10.1016/j.neuron.2016.01.028.

8. Heneka MT, Carson MJ, Khoury J, Landreth GE, Brosseron F, Feinstein DL, et al. Neuroinflammation in Alzheimer's disease. Lancet Neurol. 2015;14(4): 388-405. https://doi.org/10.1016/S1474-4422(15)70016-5.

9. Ising C, Venegas C, Zhang S, Scheiblich H, Schmidt SV, Vieira-Saecker A, et al. NLRP3 inflammasome activation drives tau pathology. Nature. 2019; 575(7784):669-73. https://doi.org/10.1038/s41586-019-1769-Z.

10. Glass CK, Saijo K, Winner B, Marchetto MC, Gage FH. Mechanisms underlying inflammation in neurodegeneration. Cell. 2010;140(6):918-34. https://doi. org/10.1016/j.cell.2010.02.016.

11. Wyss-Coray T, Rogers J. Inflammation in Alzheimer disease-a brief review of the basic science and clinical literature. Csh Perspect Med. 2012;2(1): a006346.

12. Maphis N, Xu G, Kokiko-Cochran ON, Jiang S, Cardona A, Ransohoff RM, et al. Reactive microglia drive tau pathology and contribute to the spreading of pathological tau in the brain. Brain J Neurol. 2015;138(Pt 6): 1738-55. https://doi.org/10.1093/brain/awv081. 
13. Moore KW, de Malefyt R, Coffman RL, O'Garra A. Interleukin-10 and the interleukin-10 receptor. Annu Rev Immunol. 2001;19(1):683-765. https://doi. org/10.1146/annurev.immunol.19.1.683.

14. Strle K, Zhou J-H, Shen W-H, Broussard SR, Johnson RW, Freund GG, et al. Interleukin-10 in the Brain. Crit Rev Immunol. 2001;21(5):23.

15. Ledeboer A, Brevé JJ, Wierinckx A, Jagt S, Bristow AF, Leysen JE, et al. Expression and regulation of interleukin-10 and interleukin-10 receptor in rat astroglial and microglial cells. Eur J Neurosci. 2002;16(7):1175-85. https:// doi.org/10.1046/j.1460-9568.2002.02200.x.

16. Shemer A, Scheyltjens I, Frumer GR, Kim J-S, Grozovski J, Ayanaw S, et al. Interleukin-10 prevents pathological microglia hyperactivation following peripheral endotoxin challenge. Immunity. 2020;53(5):1033-1049.e7. https:// doi.org/10.1016/j.immuni.2020.09.018.

17. Saraiva M, O'Garra A. The regulation of IL-10 production by immune cells. Nat Rev Immunol. 2010;10(3):170-81. https://doi.org/10.1038/nri2711.

18. Strle K, Zhou J-H, Broussard SR, Venters HD, Johnson RW, Freund GG, et al. IL-10 promotes survival of microglia without activating Akt. J Neuroimmunol. 2002;122(1-2):9-19. https://doi.org/10.1016/S0165-5728(01 )00444-1.

19. Bai F, Xie C, Yuan Y, Shi Y, Zhang Z. Promoter haplotypes of interleukin-10 gene linked to cortex plasticity in subjects with risk of Alzheimer's disease. Neuroimage Clin. 2018;17:587-95. https://doi.org/10.1016/j.nicl.2017.11.019.

20. Lio D, Licastro F, Scola L, Chiappelli M, Grimaldi L, Crivello A, et al. Interleukin-10 promoter polymorphism in sporadic Alzheimer's disease. Genes Immun. 2003;4(3):234-8. https://doi.org/10.1038/sj.gene.6363964.

21. Arosio B, Trabattoni D, Galimberti L, Bucciarelli P, Fasano F, Calabresi C, et al. Interleukin-10 and interleukin-6 gene polymorphisms as risk factors for Alzheimer's disease. Neurobiol Aging. 2004;25(8):1009-15. https://doi.org/1 0.1016/j.neurobiolaging.2003.10.009.

22. Zhang Y, Zhang J, Tian C, Xiao Y, Li X, He C, et al. The $-1082 \mathrm{G} / \mathrm{A}$ polymorphism in IL-10 gene is associated with risk of Alzheimer's disease: a meta-analysis. J Neurol Sci. 2011;303(1-2):133-8. https://doi.org/10.1016/j. jns.2010.12.005.

23. Michaud J-P, Rivest S. Anti-inflammatory signaling in microglia exacerbates Alzheimer's disease-related pathology. Neuron. 2015;85(3):450-2. https://doi. org/10.1016/j.neuron.2015.01.021.

24. Chakrabarty P, Li A, Ceballos-Diaz C, Eddy JA, Funk CC, Moore B, et al. IL-10 alters immunoproteostasis in APP mice, increasing plaque burden and worsening cognitive behavior. Neuron. 2015;85(3):519-33. https://doi.org/1 0.1016/j.neuron.2014.11.020.

25. Bhaskar K, Konerth M, Kokiko-Cochran ON, Cardona A, Ransohoff RM, Lamb BT. Regulation of tau pathology by the microglial fractalkine receptor. Neuron. 2010;68(1):19-31. https://doi.org/10.1016/j.neuron.2010.08.023.

26. Kuhn R, Lohler J, Rennick D, Rajewsky K, Muller W. Interleukin-10-deficient mice develop chronic enterocolitis. Cell. 1993;75(2):263-74. https://doi.org/1 0.1016/0092-8674(93)80068-P

27. Bemiller SM, Maphis NM, Formica SV, Wilson GN, Miller CM, Xu G, et al. Genetically enhancing the expression of chemokine domain of CX3CL1 fails to prevent tau pathology in mouse models of tauopathy. Neuroinflammation. 2018;15(1):278. https://doi.org/10.1186/s12974-01 8-1310-6.

28. Maxwell JR, Denson JL, Joste NE, Robinson S, Jantzie LL. Combined in utero hypoxia-ischemia and lipopolysaccharide administration in rats induces chorioamnionitis and a fetal inflammatory response syndrome. Placenta. 2015;36(12):1378-84. https://doi.org/10.1016/j.placenta.2015.10.009.

29. Yellowhair TR, Noor S, Maxwell JR, Anstine CV, Oppong AY, Robinson S, et al. Preclinical chorioamnionitis dysregulates CXCL1/CXCR2 signaling throughout the placental-fetal-brain axis. Exp Neurol. 2018;301(Pt B):110-9.

30. Jantzie LL, Maxwell JR, Newville JC, Yellowhair TR, Kitase Y, Madurai N, et al. Prenatal opioid exposure: the next neonatal neuroinflammatory disease. Brain Behav Immun. 2019:84:45-58.

31. Young K, Morrison H. Quantifying microglia morphology from photomicrographs of immunohistochemistry prepared tissue using ImageJ. J Vis Exp Jove. 2018;136:57648.

32. Beaudoin GMJ, Lee S-H, Singh D, Yuan $Y, N g$ Y-G, Reichardt LF, et al. Culturing pyramidal neurons from the early postnatal mouse hippocampus and cortex. Nat Protoc. 2012;7(9):1741-54. https://doi.org/10.1038/nprot.2 012.099

33. Mattsson N, Schöll M, Strandberg O, Smith R, Palmqvist S, Insel PS, et al. 18F-AV-1451 and CSF T-tau and P-tau as biomarkers in Alzheimer\&apos;s disease. Embo Mol Med. 2017;9(9):1212-23. https://doi.org/10.15252/ emmm.201707809.

34. Barthélemy NR, Li Y, Joseph-Mathurin N, Gordon BA, Hassenstab J, Benzinger Tammie LS, et al. A soluble phosphorylated tau signature links tau, amyloid and the evolution of stages of dominantly inherited Alzheimer's disease. Nat Med. 2020;26(3):398-407. https://doi.org/10.1038/ s41591-020-0781-z.

35. Biernat J, Mandelkow EM, Schröter C, Lichtenberg-Kraag B, Steiner B, Berling $B$, et al. The switch of tau protein to an Alzheimer-like state includes the phosphorylation of two serine-proline motifs upstream of the microtubule binding region. EMBO J. 1992;11(4):1593-7. https://doi.org/10.1002/j.1460-2 075.1992.tb05204.x.

36. Goedert M, Jakes R, Vanmechelen E. Monoclonal antibody AT8 recognises tau protein phosphorylated at both serine 202 and threonine 205. Neurosci Lett. 1995;189(3):167-70. https://doi.org/10.1016/0304-3940(95)11484-E.

37. Despres C, Byrne C, Qi H, Cantrelle F-X, Huvent I, Chambraud B, et al. Identification of the Tau phosphorylation pattern that drives its aggregation Proc Nat Acad Sci. 2017;114(34):9080-5. https://doi.org/10.1073/pnas.170844 8114.

38. Hauw J-J, Verny M, Delaère $P$, Cervera $P$, He Y, Duyckaerts C. Constant neurofibrillary changes in the neocortex in progressive supranuclear palsy. Basic differences with Alzheimer's disease and aging. Neurosci Lett. 1990; 119(2):182-6. https://doi.org/10.1016/0304-3940(90)90829-X.

39. Yamada T, McGeer PL, McGeer EG. Appearance of paired nucleated, Taupositive glia in patients with progressive supranuclear palsy brain tissue. Neurosci Lett. 1992;135(1):99-102. https://doi.org/10.1016/0304-3940(92 )90145-W.

40. Komori T. Tau-positive dial Inclusions in progressive supranuclear palsy, corticobasal degeneration and Pick's disease. Brain Pathol. 1999;9(4):663-79. https://doi.org/10.1111/j.1750-3639.1999.tb00549.x.

41. Bachstetter AD, Eldik LVV. The p38 MAP kinase family as regulators of proinflammatory cytokine production in degenerative diseases of the CNS. Aging Dis. 2010;1(3):199-211.

42. Reynolds $\mathrm{CH}$, Nebreda AR, Gibb GM, Utton MA, Anderton BH. Reactivating kinase/p38 phosphorylates T protein in vitro. J Neurochem. 1997;69(1):1918. https://doi.org/10.1046/j.1471-4159.1997.69010191.x.

43. Reynolds $\mathrm{CH}$, Betts JC, Blackstock WP, Nebreda AR, Anderton BH. Phosphorylation sites on tau identified by nanoelectrospray mass spectrometry. J Neurochem. 2000;74(4):1587-95. https://doi.org/10.1046/j.14 71-4159.2000.0741587.x.

44. Zhu X, Rottkamp CA, Boux H, Takeda A, Perry G, Smith MA. Activation of p38 kinase links tau phosphorylation, oxidative stress, and cell cycle-related events in Alzheimer disease. J Neuropathol Exp Neurol. 2000;59(10):880-8. https://doi.org/10.1093/jnen/59.10.880.

45. Sun A, Liu M, Nguyen XV, Bing G. P38 MAP kinase is activated at early stages in Alzheimer's disease brain. Exp Neurol. 2003;183(2):394-405. https:// doi.org/10.1016/S0014-4886(03)00180-8.

46. Maphis N, Jiang S, Xu G, Kokiko-Cochran ON, Roy SM, Eldik LJV, et al. Selective suppression of the $a$ isoform of p38 MAPK rescues late-stage tau pathology. Alzheimers Res Ther. 2016;8(1):54. https://doi.org/10.1186/s13195016-0221-y.

47. Arosio B, Mastronardi L, Vergani C, Annoni G. Intereleukin-10 promoter polymorphism in mild cognitive impairment and in its clinical evolution. Int J Alzheimers Dis. 2010;2010:854527.

48. Scassellati C, Zanardini R, Squitti R, Bocchio-Chiavetto L, Bonvicini C, Binetti $\mathrm{G}$, et al. Promoter haplotypes of interleukin-10 gene and sporadic Alzheimer's disease. Neurosci Lett. 2004;356(2):119-22. https://doi.org/10.101 6/j.neulet.2003.11.033.

49. Turner DM, Williams DM, Sankaran D, Lazarus M, Sinnott PJ, Hutchinson IV. An investigation of polymorphism in the interleukin-10 gene promoter. Eur J Immunogenet. 1997;24(1):1-8. https://doi.org/10.1111/j.1365-2370.1997. tb00001.x.

50. Asselineau D, Benlhassan K, Arosio B, Mari D, Ferri E, Casati M, et al. Interleukin-10 production in response to amyloid- $\beta$ differs between slow and fast decliners in patients with Alzheimer's disease. J Alzheimer's Dis Jad. 2015;46(4):837-42. https://doi.org/10.3233/JAD-142832.

51. Kunkle BW, Grenier-Boley B, Sims R, Bis JC, Damotte V, Naj AC, et al. Genetic meta-analysis of diagnosed Alzheimer's disease identifies new risk loci and implicates A $\beta$, tau, immunity and lipid processing. Nat Genet. 2019;51(3): 414-30. https://doi.org/10.1038/s41588-019-0358-2. 
52. Jansen IE, Savage JE, Watanabe K, Bryois J, Williams DM, Steinberg S, et al. Genome-wide meta-analysis identifies new loci and functional pathways influencing Alzheimer's disease risk. Nat Genet. 2019;51(3):404-13. https:// doi.org/10.1038/s41588-018-0311-9.

53. Yoshiyama Y, Higuchi M, Zhang B, Huang S-M, Iwata N, Saido TC, et al. Synapse loss and microglial activation precede tangles in a p301s tauopathy mouse model. Neuron. 2007:53(3):337-51. https://doi.org/10.101 6/j.neuron.2007.01.010.

54. Almolda B, de Labra C, Barrera I, Gruart A, Delgado-Garcia JM, Villacampa N, et al. Alterations in microglial phenotype and hippocampal neuronal function in transgenic mice with astrocyte-targeted production of interleukin-10. Brain Behav Immun. 2015;45:80-97. https://doi.org/10.1016/j. bbi.2014.10.015.

55. Laffer B, Bauer D, Wasmuth S, Busch M, Jalilvand T, Thanos S, et al. Loss of IL-10 promotes differentiation of microglia to a M1 phenotype. Front Cell Neurosci. 2019;13:430. https://doi.org/10.3389/fncel.2019.00430.

56. Guillot-Sestier M-V, Doty KR, Gate D, Rodriguez J, Leung BP, Rezai-Zadeh K, et al. II10 deficiency rebalances innate immunity to mitigate Alzheimer-like pathology. Neuron. 2015;85(3):534-48. https://doi.org/10.1016/j.neuron.2 014.12 .068 .

57. Yi S, Jiang $X$, Tang $X$, Li Y, Xiao C, Zhang J, et al. IL-4 and IL-10 promotes phagocytic activity of microglia by up-regulation of TREM2. Cytotechnology. 2020:1-14.

58. Heneka MT, Kummer MP, Stutz A, Delekate A, Schwartz S, Vieira-Saecker A, et al. NLRP3 is activated in Alzheimer's disease and contributes to pathology in APP/PS1 mice. Nature. 2013;493(7434):674-8. https://doi.org/1 0.1038 /nature11729.

59. Tarkowski E, Andreasen N, Tarkowski A, Blennow K. Intrathecal inflammation precedes development of Alzheimer's disease. J Neurol Neurosurg Psychiatry. 2003;74(9):1200-5. https://doi.org/10.1136/jnnp.74.9.1200.

60. Taipa R, SP das Neves, Sousa AL, Fernandes J, Pinto C, Correia AP, et al. Proinflammatory and anti-inflammatory cytokines in the CSF of patients with Alzheimer's disease and their correlation with cognitive decline. Neurobiol Aging. 2019;76:125-32. https://doi.org/10.1016/j.neurobiolaging.2 018.12.019.

61. Sabat R, Grütz G, Warszawska K, Kirsch S, Witte E, Wolk K, et al. Biology of interleukin-10. Cytokine Growth F R. 2010;21(5):331-44. https://doi.org/10.1 016/j.cytogfr.2010.09.002

62. Cianciulli A, Dragone T, Calvello R, Porro C, Trotta T, Lofrumento D, et al. IL10 plays a pivotal role in anti-inflammatory effects of resveratrol in activated microglia cells. Int Immunopharmacol. 2015;24(2):369-76. https://doi.org/1 0.1016/j.intimp.2014.12.035.

63. Hammer M, Mages J, Dietrich H, Schmitz F, Striebel F, Murray PJ, et al. Control of dual-specificity phosphatase-1 expression in activated macrophages by IL-10. Eur J Immunol. 2005;35(10):2991-3001. https://doi. org/10.1002/eji.200526192.

64. Kim C, Sano Y, Todorova K, Carlson BA, Arpa L, Celada A, et al. The kinase p38a serves cell type-specific inflammatory functions in skin injury and coordinates pro- and anti-inflammatory gene expression. Nat Immunol. 2008;9(9):1019-27. https://doi.org/10.1038/ni.1640.

65. Ledeboer A, Brevé J, Poole S, Tilders F, Dam A. Interleukin-10, interleukin-4, and transforming growth factor- $\beta$ differentially regulate lipopolysaccharide-induced production of pro-inflammatory cytokines and nitric oxide in co-cultures of rat astroglial and microglial cells. Glia. 2000;30(2):134-42. https://doi.org/10.1002/(SICI)1098-1136(200004)30:2< 134:.AID-GLIA3>3.0.CO;2-3.

66. Ledeboer A, Binnekade R, Brevé JJ, Bol JG, Tilders FJ, Dam A-M. Site-specific modulation of LPS-induced fever and interleukin-1 $\beta$ expression in rats by interleukin-10. Am J Physiol Reg Integr Comp Physiol. 2002;282(6):R1762-72. https://doi.org/10.1152/ajpregu.00766.2001.

67. Sanz JM, Virgilio FD. Kinetics and Mechanism of ATP-Dependent IL-1 $\beta$ release from microglial cells. J Immunol. 2000;164(9):4893-8. https://doi. org/10.4049/jimmunol.164.9.4893.

68. Licastro F, Pedrini S, Caputo L, Annoni G, Davis LJ, Ferri C, et al. Increased plasma levels of interleukin-1, interleukin-6 and a-1-antichymotrypsin in patients with Alzheimer's disease: peripheral inflammation or signals from the brain? J Neuroimmunol. 2000;103(1):97-102. https://doi.org/10.1016/S01 65-5728(99)00226-X.

69. Licastro F, Chiappelli M. Brain immune responses cognitive decline and dementia: relationship with phenotype expression and genetic background.
Mech Ageing Dev. 2003;124(4):539-48. https://doi.org/10.1016/S0047-6374 (03)00034-4.

70. Quintanilla RA, Orellana DI, González-Billault C, Maccioni RB. Interleukin-6 induces Alzheimer-type phosphorylation of tau protein by deregulating the cdk5/p35 pathway. Exp Cell Res. 2004;295(1):245-57. https://doi.org/10.1016/ j.yexcr.2004.01.002.

71. Fassbender K, Walter S, Kühl S, Landmann R, Ishii K, Bertsch T, et al. The LPS receptor (CD14) links innate immunity with Alzheimer's disease. FASEB J. 2004;18(1):203-5. https://doi.org/10.1096/fj.03-0364fje.

72. Walter S, Letiembre M, Liu Y, Heine H, Penke B, Hao W, et al. Role of the toll-like receptor 4 in neuroinflammation in Alzheimer's disease. Cell Physiol Biochem. 2007;20(6):947-56. https://doi.org/10.1159/000110455.

73. Kigerl KA, de Rivero Vaccari JP, Dietrich WD, Popovich PG, Keane RW. Pattern recognition receptors and central nervous system repair. Exp Neurol. 2014;258:5-16. https://doi.org/10.1016/j.expneurol.2014.01.001.

74. Zhao Y, Cong L, Jaber V, Lukiw WJ. Microbiome-derived lipopolysaccharide enriched in the perinuclear region of Alzheimer's disease brain. Front Immunol. 2017;8:1064. https://doi.org/10.3389/fimmu.2017.01064.

75. Brown GC. The endotoxin hypothesis of neurodegeneration. J Neuroinflammation. 2019;16(1):180. https://doi.org/10.1186/s12974-019-1 564-7.

76. Patil KR, Mahajan UB, Unger BS, Goyal SN, Belemkar S, Surana SJ, et al. Animal models of inflammation for screening of anti-inflammatory drugs: implications for the discovery and development of phytopharmaceuticals. Int J Mol Sci. 2019;20(18):4367. https://doi.org/10.3390/ijms20184367.

\section{Publisher's Note}

Springer Nature remains neutral with regard to jurisdictional claims in published maps and institutional affiliations.
Ready to submit your research? Choose BMC and benefit from:

- fast, convenient online submission

- thorough peer review by experienced researchers in your field

- rapid publication on acceptance

- support for research data, including large and complex data types

- gold Open Access which fosters wider collaboration and increased citations

- maximum visibility for your research: over $100 \mathrm{M}$ website views per year

At BMC, research is always in progress.

Learn more biomedcentral.com/submissions 